\title{
As guerras do Rio: mídia, favela e militarização do cotidiano
}

\section{The Rio wars: media, favela and militarization of every daily life}

\author{
Las guerras de Río: medios, favela y militarización de lo cotidiano
}

\author{
Carla Baiense Felix | carlabaienses@yahoo.com.br \\ Universidade Federal Fluminense, Programa de Pós-graduação em Mídia e Cotidiano. Niterói, Brasil.
}

\section{Resumo}

Este trabalho analisa o uso da expressão Guerra do Rio como elemento estruturante das narrativas jornalísticas sobre o tráfico de drogas de varejo nas favelas do Rio de Janeiro. A partir de reportagens publicadas em dois jornais cariocas - O Globo e Jornal do Brasil -, em dez diferentes anos, ao longo de quatro décadas (dos anos 1980 a 2010)i , busca-se recuperar as condições de emergência desta representação e os sentidos postos em circulação, bem como problematizar suas consequências. Utilizando a teoria da agenda (Mc Combs e Shaw) e a análise do enquadramento (Entmann) pretendemos compreender como a construção de uma cidade em guerra nos discursos jornalísticos influenciou a agenda pública em diferentes períodos, justificando a militarização do cotidiano da população moradora de favelas, submetendo-a a uma sociabilidade violenta (Machado da Silva).

Palavras-chave: Guerra do Rio; Rio de Janeiro; O Globo; Jornal do Brasil; Favela; Cotidiano; Teoria da Agenda; Enquadramento; Segurança Pública; Militarização.

i Uma análise mais ampla sobre o noticiário produzido no período foi empreendida em: Felix, Carla Baiense. Territórios proibidos: a construção da favela no noticiário e seus efeitos sociais . [tese]. Rio de Janeiro: Universidade Federal do Rio de Janeiro; 2012. Disponível em: $h$ ttp://www.pos.eco.ufri.br/site/teses dissertacoes interna.php?tease=2. Aqui, utilizamos a amostra para uma análise focada nas narrativas sobre guerra. 


\begin{abstract}
This paper analyzes the use of the term Guerra do Rio as a structuring element of the journalistic narratives about the drug trafficking in the slums of Rio de Janeiro. Based on reports published in two Rio newspapers - O Globo and Jornal do Brasil - in ten different years, over four decades, it seeks to recover the conditions of emergence of this representation and the meanings put into circulation, as well as to problematize its consequences. Using the agenda setting (Mc Combs and Shaw) and the frame analysis (Entmann) we intend to understand how the construction of a city at war in journalistic discourses influenced the public agenda in different periods, justifying the militarization of the every daily life of the population living in slums, subjecting it to a violent sociability (Machado da Silva).
\end{abstract}

Keywords: Rio war; Rio de Janeiro; O Globo; Jornal do Brasil; Slum; Every Day Life; Agenda Setting; Frame Analysis; Public Security; Militarization.

\title{
Resumen
}

Este trabajo analiza el uso de la expresión Guerra de Río como elemento estructurante de las narrativas periodísticas sobre el tráfico de drogas al por menor en las favelas de Rio de Janeiro. A partir de reportajes publicados en dos periódicos cariocas - O Globo y Jornal do Brasil-, en diez años diferentes, a lo largo de cuatro décadas, se busca recuperar las condiciones de emergencia de esta representación y los sentidos puestos en circulación, así como problematizar sus consecuencias. El uso de la teoría de la agenda (Mc Combs y Shaw) y el análisis del encuadramiento (Entmann) pretendemos comprender cómo la construcción de una ciudad en guerra en los discursos periodísticos influenció la agenda pública en diferentes períodos, justificando la militarización del cotidiano de la población moradora de favelas, sometiéndola a una sociabilidad violenta (Machado da Silva).

Palabras clave: Guerra en Rio; Rio de Janeiro; O globo; Jornal do Brasil; Favelas; Vida Cotidiana; Teoría de la Agenda; Encuadramiento; Seguridad Pública; Militarización.

Contribuição dos autores: a autora é responsável por todo o texto.

Declaração de conflito de interesses: Não há.

Fontes de financiamento: Não há

Considerações éticas: Não há

Agradecimento/Contribuições adicionais: não há

Histórico do artigo: Submetido: 25.set.2017 | Aceito: 25.set.2017 | Publicado: 29.set.2017

Apresentação anterior: não houve

Licença CC BY-NC atribuição não comercial. Com essa licença é permitido acessar, baixar (download), copiar, imprimir, compartilhar, reutilizar e distribuir os artigos, desde que para uso não comercial e com a citação da fonte, conferindo os devidos créditos de autoria e menção à Reciis. Nesses casos, nenhuma permissão é necessária por parte dos autores ou dos editores. 
O recente lançamento da editoria Guerra do Rio pelo Jornal Extra, das organizações Globo, reacendeu os debates sobre os sentidos produzidos e as consequências desta representação sobre o cotidiano das favelas do Rio de Janeiro. No vídeo "É Guerra”, o veículo justifica, através de depoimentos de jornalistas, apresentação de infografias e reprodução de notícias, as razões que teriam motivado a criação da nova seção. Com uma estética que lembra a dos jogos eletrônicos, com sons de sirene, helicópteros e disparos de fuzil, intercalados com uma trilha fúnebre, a narrativa define, de modo específico, onde se dá e em que consiste a Guerra do Rio: os conflitos dentro e nas bordas das 843 favelas territorializadas pelo tráfico de drogas de varejo.

O Diretor de Redação Octavio Guedes explicita a posição do jornal: para resolver o problema, tem que chamar o problema pelo termo correto. (...) Não pode chamar mais isso de editoria de polícia. (...) Uma coisa é guerra, outra coisa é polícia ${ }^{1}$ E dá como exemplos episódios recentes de mortes produzidas por conflitos entre traficantes, policiais e milicianos em áreas favelizadas. O repórter Rafael Soares chega a apresentar um ranking com as 'top five' ou seja, regiões com maior taxa de letalidade, segundo levantamento de um instituto de segurança do Estado: Cidade de Deus, Magueirinha, Morro da Providência, Mangueira e Complexo da Penha.

A pergunta mais óbvia diante desta exposição seria: em que medida nomear de Guerra os episódios produzidos pelas disputas por pontos de venda de drogas ajuda a resolver o problema da segurança pública no Estado do Rio de Janeiro? Articulando a proposição do jornal com nossa pesquisa, poderíamos perguntar de forma mais ampla: quais os sentidos e consequências políticas produzidos em mais de 30 anos de cobertura policial, tendo como elemento estruturante a Guerra do Rio?

Antes de iniciarmos a análise noticiosa, propriamente, precisamos problematizar a influência dos meios de comunicação de massa sobre a formação de uma opinião pública e sua articulação com uma agenda política. Os estudos dos efeitos desenvolvidos na tradição norte-americana partem da premissa de que boa parte dos assuntos que assumem papel central na agenda pública não estão acessíveis à experiência direta das pessoas. Mac Combs ${ }^{2}$ considera que os cidadãos definem quase todas as suas preocupações a partir de uma 'realidade de segunda-mão', ou seja, uma realidade estruturada a partir das narrativas jornalísticas. Lippmann ${ }^{3}$ chama esta representação da realidade de pseudoambiente que, a despeito da sua incapacidade de reproduzir o ambiente real, é eficaz em determinar os mapas cognitivos a partir dos quais interpretamos os fatos.

A partir de diversas experiências empíricas, Mac Combs² pode comprovar que, se não definem como pensar determinadas questões, os meios são eficientes, ao menos, em dizer sobre quais questões pensar. É a partir da análise de enquadramento (frame analysis), derivada da tradição sócio-interacionaista, que os estudos em comunicação avançam na perspectiva de investigar os mecanismos a partir dos quais os meios organizam a leitura e a interpretação dos fatos. Ou seja, toca o cerne da produção jornalística, apontando a seleção e saliência de notícias como os dois processos capazes de promover "uma definição particular do problema, uma interpretação casual, uma avaliação moral e/ou uma recomendação de tratamento para o item descrito"4.

Não se trata, portanto, de considerar que os meios de comunicação de massa produzem uma representação violenta das favelas apartada da realidade cotidiana das comunidades. Mas reconhecer que a experiência cotidiana com a violência é mediada pelos discursos jornalísticos, produzidos dentro de condições específicas, tanto a partir de rotinas produtivas quanto de interesses particulares.

Neste artigo, procurarei examinar as condições de emergência da Guerra do Rio nas narrativas sobre crime dentro ou no entorno de favelas, considerando os fatores sociais, políticos e econômicos, a partir dos anos 1990, quando surge esta representação. Examinarei os sentidos produzidos, a partir da análise do enquadramento, levando em conta a polifonia dos discursos. Por fim, buscarei, a partir da própria materialidade dos textos, mapear os desdobramentos desta discursividade sobre o cotidiano das populações faveladas do Rio de Janeiro. 
Para realizar esta investigação, selecionei um total de 501 reportagens publicadas em O Globo e 263 veiculadas pelo JB, entre os anos de 1984/1986, 1993/1995, 2002/2004 e 2010, analisando duas semanas por ano ${ }^{\text {ii }}$. A busca foi feita tendo como palavra-chave o termo favela e seus correlatos (comunidade, morro, ocupação). Note-se que expressões como violência e crime não foram utilizadas, mas acabaram por se constituir no tema central da maior parte do corpus. A partir dos anos 1990, o enquadramento da favela pelo frame da criminalidade/violência supera os $80 \%$ da amostra em quase todos os anos analisados.

Desde os anos 1980, a violência urbana começou a ter destaque no noticiário carioca. Em 1981, o Jornal do Brasil, criou uma rubrica especial para cobrir os crimes ocorridos na cidade: violência. Benevides ${ }^{5}$ considera que neste momento a imprensa começa a tematizar a violência como uma questão importante na agenda pública. Nossa amostra, que como enfatizamos tinha a favela não a violência como palavra-chave, encontrou duas coberturas representativas sobre as representações da criminalidade no período: a do seminário 'O Rio conta o Crime', promovido pelas Organizações Globo em parceria com o Ibope, publicada em 29 de agosto de $1984^{6}$, e a da pesquisa Opinião Carioca, realizada pelo JB em parceria com a Gerp Serviços de Marketing, veiculada em 14 julho de 19867.

Em ambos os casos, percebe-se o agendamento da segurança como questão pública relevante. Mas o que estava em jogo eram as representações do crime comum, sobretudo os furtos e assaltos. Não confundindo o fenômeno com sua visibilidade, os dados das duas pesquisas mostram que havia uma relação estreita entre a percepção dos leitores e a agenda da mídia em relação à segurança pública.

De fato, a sondagem do JB, que ouviu 500 pessoas, em dois dias, e projetou os dados sobre a base de moradores do Rio de Janeiro, Niterói e Baixada Fluminense, concluiu que houve um aumento de 30\% no número de vítimas de assalto em relação ao ano anterior. Já a pesquisa do Globo, ouvindo 228.327 pessoas, revelou que cerca de $60 \%$ já tinham sofrido um assalto e $77 \%$ tinham um parente vítima de assaltantes. Embora o termo favela apareça em ambas as reportagens, é na condição de vítima preferencial da violência, porque obrigada a circular pela cidade a pé ou de ônibus, que seus moradores comparecem.

Ao longo dos anos 1990, uma série de transformações urbanas, sociais, econômicas e políticas vão deslocar o interesse dos jornais em relação ao tema da violência. Do ponto de vista populacional, as favelas passam a apresentar um crescimento muito superior ao da 'cidade formal'. Conforme o IBGE, entre 1991 e 2000, a população favelada do Rio cresceu 23,78\%, com um aumento de 882.483 para 1.092 .783 habitantes. Mas não será esse o foco das reportagens do período. A chegada do lucrativo comércio de cocaína à cidade, produziu o que Machado da Silva ${ }^{8}$ caracterizou como o desencapsulamento do tráfico de drogas. Sua nova dinâmica de funcionamento baseia-se na territorialização das favelas, a partir das quais se dá a venda de varejo, e no uso da força para defesa dos territórios. Esse fenômeno, somado ao adensamento populacional, dá nova visibilidade à favela no noticiário da cidade.

Em 1993, ano que esta visibilidade se torna mais problemática, nas duas semanas analisadas, o termo favela aparece em 58 das matérias publicadas por O Globo. Em 1995, último ano analisado na década, são 54. No JB, o termo e seus correlatos aparecem em 38 das reportagens, em 1993. Dois anos depois, em 29. A título de comparação, encontramos 6 reportagens sobre favela no JB em 1984, primeiro ano de nossa análise. Em 1986, 11 continham o termo. No Globo, foram 26, em 1984, e 19, em 1986.

Além da relevância que adquire, a favela passa a ser representada em outros termos. Se na década anterior não havia uma associação mecânica entre favela e violência, embora se considerasse que a pobreza gerasse o crime, nos anos 1990 essa relação naturalizou-se. A consequência direta desta representação é a hegemonia do discurso que enquadra a favela pelo frame da violência. No primeiro ano da pesquisa, $84 \%$ das reportagens de O Globo enquadram a favela a partir da violência, percentual que chegará a $88 \%$ em

ii Para compor as semanas de pesquisa, sorteei 15 datas, compondo artificialmente duas semanas completas. 
1995. No JB, a hegemonia é ainda maior, com 87\% das reportagens utilizando o frame no início da década, alcançando $92 \%$ no último ano pesquisado.

Neste enquadramento, a favela aparece ora como um território sitiado por traficantes, e seus moradores, como vítimas da violência, ora surge como fonte de risco para a cidade. O traficante é caracterizado em termos de inimigo do Estado, cuja tarefa é retomar os territórios, libertar a população e restabelecer a ordem. Esta representação da favela em contraponto ao asfalto põe em circulação a noção de uma cidade dual ${ }^{9}$. Utilizada na teoria sociológica para explicar a produção de desigualdades no contexto da globalização, a noção é apropriada pelo senso-comum para caracterizar diferentes áreas urbanas, ensejando as representações da cidade partida.

Neste sentido, dois vocábulos adquirem valor semântico específico, produzindo novos sentidos associados à favela: o termo 'fator de risco', precursor da 'área de risco', que definirá uma nova geografia da cidade, e guerra, a partir do qual serão estruturadas as narrativas que envolvem conflitos armados nessas localidades.

Embora localizada, a presença de um crime organizado e bem armado já é vista como problemática não apenas pela ameaça que se configura ao morador de favela. Também é pensada como potencialmente perigosa para o morador da cidade formal. Essa dubiedade da favela, que relativiza a representação do favelado enquanto vítima, vai aparecer em diferentes momentos ao longo do ano, caracterizando uma espécie de transição da piedade ao risco ${ }^{10}$.

Dois dos episódios mais emblemáticos do ano de 1993, ambos relacionados à favela, representam a transição de que falamos. Entre a Chacina da Candelária, em 23 de julho, e o confronto entre policiais e bandidos em Acari, em 28 de setembro, as discussões sobre a violência saem da esfera social e restringemse à criminal. Enquanto na cobertura da Candelária as narrativas jornalísticas questionavam o papel da sociedade perante a violência que vitimou os meninos na calçada, no confronto de Acari, é a sociedade que questiona o papel do Estado na contenção da violência. É neste contexto que encontramos, pela primeira vez na amostra, o uso do termo guerraiii.

A narrativa do Jornal O Globo constrói, em textos e imagens, um cenário verdadeiramente de guerra, para descrever o confronto entre 17 traficantes da favela Coroado e 14 policiais da DRE-Niterói, que receberam o reforço de 30 soldados do $9^{\circ} \mathrm{BPM}, 50$ do Batalhão de Choque, 40 dos batalhões de Olaria e São João de Meriti, além de 12 atiradores do Bope e dois helicópteros, com um total de oito atiradores de elite. O resultado desta operação foi assim descrito: "Milhares de tiros foram disparados e cerca de 50 granadas foram detonadas ontem de manhã em quatro horas de guerra entre a polícia e traficantes da Favela do Coroado, em Acari. Ao fim da batalha, cinco bandidos estavam mortos e havia 14 pessoas feridas: cinco favelados, cinco traficantes e quatro policiais" ${ }^{11}$.

Dentro do escopo desta pesquisa, podemos considerar a cobertura do episódio de Coroado como um divisor de águas no tratamento editorial das reportagens sobre favela. O próprio evento em si, obviamente, traz elementos bastante peculiares, que justificariam, sob a ótica jornalística, um tratamento diferenciado. Mas argumentamos que a forma de narrar os fatos, as marcas visuais, e o uso de um vocabulário ligado à guerra estabelecem uma nova gramática discursiva. Há, efetivamente, uma militarização do discurso midiático, que passa a representar o Rio de Janeiro como um território em guerra e põe em lados opostos $o$ asfalto e a favela.

Embora o episódio se desenvolva em Acari, o selo da reportagem - uma arma saindo do morro empunhada na direção do leitor - não deixa dúvidas: a cidade está sob a mira dos traficantes. A foto de uma mãe em fuga com o filho nos braços e outras quatro imagens chocantes, na última página do primeiro caderno,

iii A chacina de Vigário Geral, que ocorre em 29 de agosto de 1993, será lembrada pelo Jornal O Globo na capa do Caderno Retrospectiva, sob o título "A batalha do Rio". 
confeccionado em quatro cores - um recurso gráfico especial para ao período - revelam o espanto da 'cidade' diante da violência dos traficantes.

O segundo sintoma da transição que assinalamos é a mudança nos discursos sobre as soluções para a violência. Se no caso da Candelária o Ministro da Justiça, Maurício Corrêa, é categórico em afirmar ao JB que "a hipótese de intervenção está totalmente descartada"12, meses depois, a pretexto das discussões do papel das Forças Armadas definindo pela Constituição, o cientista político José Murilo de Carvalho revela ao Globo uma mudança de postura em relação ao tema: "Até recentemente eu era totalmente contrário à utilização das Forças Armadas na defesa da lei e da ordem"13.

$\mathrm{Na}$ cobertura do episódio sobre o confronto entre policiais e bandidos na favela de Coroado, o diretor da Polícia Federal, coronel Wilson Romão, declara que a PF e o Exército já tinham um plano de ocupação conjunta das favelas cariocas, aguardando apenas um pedido formal do governador Leonel Brizola. A ação ocorrerá efetivamente com a Operação Rio. É no contexto de guerra que se justifica a intervenção das Forças Armadas, como reza o artigo $\mathrm{n}^{\mathrm{0}} 142$ da Constituição. Conforme o coronel Romão, "os morros cariocas são verdadeiras 'zonas liberadas', onde quem manda é a criminalidade, e o problema persistirá enquanto Brizola insistir em enfrentá-lo sozinho. Romão lembrou que a revolução cubana começou assim”"13.

O comentário, revela, no entanto, que a participação da mídia na representação da guerra não se devia apenas ao dever de noticiar, ou à necessidade de mobilizar a audiência, mas resultava, ainda, de um jogo de forças políticas bem definido que invoca, inclusive, a 'ameaça comunista' como argumentação. No contexto do retorno de Leonel Brizola ao governo do Estado (durante o mandato de 1991 a 1994) e da campanha a sua sucessão em curso, o clima de terror expressa o desejo de interferir no processo eleitoral, como apontaria um dos traficantes caçados pela polícia à época ${ }^{\mathrm{iv}}$, o Uê.

Os efeitos subjetivos deste discurso se revelam tanto na cultura do medo entre as classes médias quanto na estigmatização da favela. Do ponto de vista político, resultará numa nova divisão geográfica da cidade, a partir da definição de áreas de risco, e na legitimação do uso do aparato militar para o combate ao tráfico nas favelas.

A efetivação deste discurso se dará em dezembro de 1994, com a ocupação do morro Pavão-Pavãozinho, em Copacabana, e Cantagalo, em Ipanema, ambos na zona Sul do Rio de Janeiro. Com o aparato de 1.500 homens do Exército, Bope, PM e Polícia Civil, se deflagra o início da Operação Rio. Destaque na capa dos jornais em 16 de dezembro, a cobertura manteve o uso do selo que reproduz uma arma apontada contra o leitor, criado um ano antes para a cobertura do episódio em Coroado.

Não foi a primeira vez que as Forças Armadas subiram os morros. Dois anos antes, durante a realização da Conferência das Nações Unidas sobre o Meio Ambiente e o Desenvolvimento (Rio-92), que aconteceu entre 3 e 14 de junho de 1992, no Rio de Janeiro, diferentes favelas da cidade estiveram sob cerco dos militares. O próprio debate, iniciado em 1993, sobre a necessidade de mobilizar as Forças Armadas no combate ao crime, relembrava o "clima de segurança" naquele período.

A diferença é que em 1994 não havia um evento especial que justificasse o recurso à estrutura bélica, era a própria militarização do cotidiano da favela que se estava naturalizando. Os discursos, no entanto, apresentam certa polifonia, revelando que os jornais tanto incentivavam a intervenção militar quanto vigiavam o comportamento destes frente à população favelada. $\mathrm{O} J \mathrm{~B}$, por exemplo, denunciava que, embora alegassem a posse de mandatos de busca e apreensão "os militares revistaram barracos tentando encontrar armas e drogas. No entanto, nenhum desses documentos foi mostrado aos jornalistas que acompanharam a ação"16.

Também precisamos problematizar o papel da mídia neste processo. Como vimos, os jornais não apenas pautaram o debate do assunto, dentro do próprio jornalismo, mas efetivamente atuaram como protago-

iv Durante uma "entrevista coletiva" convocada por Ernaldo Pinto Medeiros, o Uê, que comandava o tráfico de drogas no Morro do Adeus, o traficante critica a corrupção na polícia e afirma que o clima de terror foi produzido para interferir no processo eleitoral ${ }^{15}$. 
nistas, cobrando das autoridades uma ação efetiva. Assim, vemos o Exército ocupando o Morro da Caixa D’Água apenas um dia depois de $\mathrm{O}$ Globo $^{17}$ publicar uma matéria em que quatro traficantes negavam o estabelecimento de um toque de recolher na favela vizinha, o Morro do Dezoito. Voltando à questão do agendamento, não podemos assegurar que há uma relação de causa e efeito entre os dois episódios, mas são as próprias marcas do discurso que nos indicam o poder da mídia em influenciar tanto a 'opinião pública' quanto a reação do Estado.

A invasão do Complexo do Alemão, reduto de Uê, revela de modo contundente a polifonia de que falamos. Descrita como a maior da Operação Rio, a ocupação mobilizou 4.20o homens das três forças armadas. Em chamada de capa, $O$ Globo descreveria a forma como os militares ingressaram na favela: "A primeira ação conjunta das três Forças Armadas começou às $5 \mathrm{~h}$ com veículos blindados cercando os acessos às favelas e 11 helicópteros para desembarcar os soldados que revistaram casas sob protestos dos moradores. À noite, os militares proibiram reuniões nas favelas, mandaram o comércio fechar e sugeriram que ninguém saísse de casa" ${ }^{18}$.

Portanto, embora o enquadramento predominante no período seja o da violência, há um agendamento de diferentes questões públicas. A segurança, sem dúvida, é a questão que toma conta do debate, quando o assunto diz respeito à favela, mas os direitos humanos também estão em pauta. É necessário que se opere uma distinção entre 'nós', cidadãos de bem que pagamos nossos impostos, de um lado, e 'eles', que ameaçam nossa segurança, do outro, para que os direitos humanos percam espaço no debate público.

Do ponto de vista jornalístico, a narrativa que relaciona crime e favela vai caracterizar-se por uma estrutura bastante singular, a partir de meados dos anos 1990. Se antes estabelecia o favelado como vítima do sofrimento produzido pela violência, cada vez mais o leitor é convocado a tomar o lugar da vítima. Sem dúvida, o poder de fogo e os confrontos espetaculares entre traficantes causam interrupções na rotina de milhares de moradores da cidade. Meu argumento, no entanto, é que não se pode isolar a violência do tráfico da sua representação midiática, e que esta vem agendando de modo efetivo a ação do Estado frente à questão, tendo como consequência a militarização do cotidiano nas favelas.

Na década seguinte, um fato iria reiterar o processo que descrevemos, produzindo efeitos tanto no cotidiano das favelas quanto no processo produtivo das empresas de comunicação, a morte do jornalista Tim Lopes. Experiente repórter da TV Globo, premiado em 2001 pela reportagem 'Feira das drogas', exibida no Fantástico, foi reconhecido por traficantes na Vila Cruzeiro, durante uma reportagem sobre consumo de drogas e exploração sexual de menores no baile funk da região, quando filmava com câmera ocultav .

Reconhecido por traficantes, foi preso, torturado, morto e esquartejado no alto da favela da Grota, no Complexo da Penha. Seu corpo foi queimado num 'microondas'vi, de onde restaram apenas fragmentos da câmera, um cordão e a arcada dentária. A crueldade do ato não deixa dúvidas a respeito do crime. Queremos discutir, aqui, seu significado do ponto de vista simbólico e as consequências dele em termos políticos e discursivos.

Após a morte de Tim Lopes, o secretário de Segurança Pública, Roberto Aguiar, estabeleceu um prazo de quatro meses para captura do principal acusado do crime, Elias Maluco. Dia 19 de setembro, com apoio de 250 policiais, a "Operação Sufoco" executou a ordem, prendendo o criminoso numa casa na favela da Grota, a partir de denúncias. O episódio foi amplamente noticiado, com chamada principal de capa no O Globo e sete páginas de cobertura. No JB, foram quatro páginas de repercussão, além de manchete principal do dia.

v Uma versão para os fatos que antecederam e sucederam a morte do jornalista está descrita no site do http://www.timlopes.com. br/casotimlopesmobilizatodoopais.htm.

vi Espécie de forno feito de pneus, onde os traficantes queimavam os corpos de suas vítimas. 
Do ponto de vista jornalístico, o episódio se traduziu num noticiário sobre a favela cada vez mais centrado nas fontes oficiais, vale dizer, a polícia. Se por um lado isto é reflexo da dificuldade de acesso do repórter ao local, por outro, revela uma mudança de postura em relação ao próprio sofrimento das vítimas da favela.

No Jornal do Brasil chama atenção o aumento no número de reportagens que tratavam da favela: de 25, em 2002, para 60 em 2004. O enquadramento das reportagens a partir da violência também cresce, de 80\% para 88\%. O Globo começará 2002 com 68\% dos enquadramentos, chegando a 80\%, em 2004. O número de reportagens também salta de 42 para 79. Também é no período que o termo guerra, como estruturante dos relatos sobre os episódios de violência nas favelas, será assumido de maneira mais categórica pelos jornais. A partir de agora, aparecerá como "A Guerra do Rio".

Selecionamos para análise a manchete "mais uma vítima da violência no Rio" sobre o assalto e agressão ao juiz Luiz Fux, do Superior Tribunal de Justiça, dentro de seu apartamento, em Copacabana, publicada no JB em 25 de maio ${ }^{18}$. Com o selo "A Guerra do Rio", a chamada agendava a questão da "crise" da segurança pública, "resolvida" em abril de 2003, com a substituição do Secretário de Segurança Josias Quintal por Anthony Garotinho, marido da governadora Rosinha Matheus. O estopim da crise seria a informação, não confirmada, de uma intervenção federal no Rio.

Após a substituição, seguiram-se dois confrontos - os armados, nas favelas, e os discursivos, na mídia. Três questões tomaram a agenda pública, nos jornais: a possibilidade de intervenção das Forças Armadas nos morros e favelas do Rio, o desarmamento da população civil e o consumo de drogas no asfalto como financiador do tráfico de armas na favela.

A representação mais contundente deste debate aparece na edição de 06 de abril de 2003, a mesma em que O Globo avalia os 100 primeiros dias do governo Lula. Na capa do JB, duas reportagens se relacionam: o cerco final a Saddam e a matéria exclusiva sobre o 'loteamento' dos pontos de venda de drogas de Copacabana a Ipanema. Lado-a-lado, a Guerra do Iraque e a Guerra do Rio revelam dois momentos distintos dos conflitos. Enquanto Saddam está prestes a se render, nossa guerra particular está longe de acabar.

Embora O Globo, na mesma edição, não utilize a expressão guerra do Rio, também faz a associação entre as duas guerras na capa, produzindo uma construção discursiva bastante consistente a respeito da relação entre os dois assuntos. A "Guerra do Rio" vai aparecer textualmente na reportagem dentro da edição. A matéria "A conta da insegurança" 20 traz como selo uma imagem de fuzil apontado em direção a motoristas, ao que parece na Linha Vermelha, tendo ao fundo uma favela. Sobre a imagem, a expressão 'A Guerra do Rio' é usada como recurso editorial para enquadrar os sentidos.

Se a 'A Guerra do Rio' foi efetivamente nomeada em 2003, em 2004 ela apareceria nas reportagens de modo ainda mais contundente. A partir das informações fornecidas por sete batalhões da PM e pela Inspetoria da Polícia Civil, O Globo chegaria à conclusão de que havia na cidade 92 favelas "onde viraram rotina os conflitos entre policiais e bandidos ou entre os próprios traficantes. Esse número representa 18\% do total de comunidades carentes" ${ }^{21}$.

Longe de problematizar as questões que permitiram ao tráfico a territorizalição destas localidades, as reportagens produzem uma estranha geografia, que não considera as favelas como parte do tecido urbano. Essa premissa se traduz em construções como 'Na guerra entre as quadrilhas da Rocinha e do Vidigal, a violência também chega ao asfalto’(idem) ou no uso da expressão “a faixa de Gaza carioca” ${ }^{22}$ para denominar territórios favelados.

Um episódio exemplar mostra a representação dúbia dos moradores da favela no meio da Guerra do Rio. Em 15 de outubro de 2004, O Globo publica uma reportagem sobre o sepultamento do traficante Irapuan David Lopes, o Gangan, chefe da venda de drogas no Morro do Zinco, no Estácio. Com o título de 'Gangan é sepultado com gritos de guerra', o jornal assim descreve a relação dos favelados com o tráfico. "[...] Mais de 300 pessoas, em sua maioria mulheres, crianças e adolescentes, lotaram Kombis e ônibus alugados para comparecer ao velório e ao sepultamento do bandido de 35 anos, morto anteontem numa suposta troca 
de tiros com policiais civis no Morro de são Carlos, no Estácio [...] O grupo ainda cantou trechos do Hino Nacional e do Hino do Flamengo, adaptando a letra para aclamar o traficante como herói”’3.

Neste mundo apartado da cidade, há um território, uma população, uma liderança e até um hino. Esta estrutura discursiva, que estabelece uma alteridade radical, se repete em muitos outros episódios. Podemos vê-la alguns meses antes, durante a cobertura da morte de Luciano Barbosa da Silva, o Lulu, que controlava o tráfico na Rocinha, considerado o mais rentável do Rio de Janeiro. Apresentado como um traficante querido pela comunidade, foi morto pela polícia, após uma denúncia anônima sobre seu esconderijo. A Guerra do Rio é o antetítulo de toda cobertura, que ocupa quatro páginas da edição de 15 de abril de 2004.

O Caderno Barra, do Jornal do Brasil, também dedicou cinco páginas ao episódio. Na foto de capa, a imagem dos policiais em uniforme de guerra contrasta com a da população de chinelos de dedo. $\mathrm{O}$ texto, porém, mostra a fragilidade de outra população: a da família Queiroz, vizinha da Rocinha. Esta vitimização do morador do asfalto tem sua síntese num trecho da reportagem, segundo o qual, "A mira da guerra iguala favela e asfalto" ${ }^{24}$.

Não é a violência, mas o medo que aproxima ambas as vítimas. Mas enquanto uns não tem nada a ver com essa guerra (os moradores do asfalto), outros, como se viu, estão envolvidos até o pescoço. Se não por compactuarem com os criminosos, ao menos por permanecerem no cenário do crime. Em editorial, o jornal deixa claro seu posicionamento a respeito da favela: "A cidade está partida não pelo antagonismo asfalto $\mathrm{x}$ favela, mas porque a favela tornou-se uma linha divisória que impede o contato entre as diversas áreas da "cidade" 25 . A opinião é endossada na coluna de Hildegard Angel: "Gente, vocês não podem imaginar como repercute a ideia lançada aqui, com a apresentação de um projeto inédito de erradicação das favelas de São Conrado. [...] O fato real é que as favelas nas encostas deixaram de ser apenas um problema grave social. São uma questão de segurança. Isto é, da insegurança, dos cidadãos cariocas, alvos humanos do tráfico armado até os dentes, com seus AR 15 apontados pras suas cabeças, lá do alto das encostas, em posição privilegiada de domínio”26.

Se não chegou a garantir a "erradicação das favelas", o discurso de medo ao menos legitimou o emprego da Força Nacional de Segurança, em maio daquele ano, no Rio de Janeiro. A solução envolvia uma tropa formada por policiais militares emprestados de vários estados, sob o comando da autoridade loca ${ }^{\text {vii. }}$.

Só no final da década é que o noticiário passaria a empregar um vocabulário mais diversificado para a cobertura de eventos envolvendo favelas. Se não puderam 'libertar' os moradores, as Unidades de Polícia Pacificadora (UPPs), instaladas em comunidades a partir de 2008, tiveram sucesso em libertar a pauta dos jornais. Nos deteremos, então, na análise dos fatores sociais, políticos e econômicos em que não apenas as UPPs, mas também os discursos sobre libertação emergem.

Ao longo de 2010, último ano de nossa análise, os jornais publicaram várias reportagens sobre locais descolados para se visitar nos morros, os pontos que oferecem uma vista privilegiada da cidade, os melhores botecos da região. Mas ainda é contra o pano de fundo da guerra que se dá a narrativa sobre os tempos de paz. Em 61\% dos enquadramentos, a violência é que estabelece os sentidos produzidos ${ }^{\text {viii. }}$.

Naquele ano, as comunidades de Tabajaras, Borel, Formiga, Andaraí, Salgueiro, Turano e Morro dos Macacos, todas na Grande Tijuca, receberam UPPs, além do Morro da Providência, no Centro. Assim como aconteceu na Zona Sul, na Zona Norte se reproduzia o esquema de cobertura policial dentro de uma mesma região, visando à pacificação de áreas chave da cidade, dentro do projeto de limpeza da cidade para atração de megaeventos internacionais.

vii Vale ressaltar que a Força Nacional de Segurança Pública só veio a atuar no Rio de Janeiro em 2007, sua quarta missão, apoiando a operação preparatória para os jogos Pan-americanos. Encerrado o evento, foi criada uma missão específica para policiamento de pontos turísticos, orla, vias expressas e Complexo do Alemão.

viii Este é o ano em que o JB deixou de circular sua edição em papel, portanto, optamos por não fazer uma análise quantitativa das reportagens do jornal. 
A presença de soldados armados com fuzis e de tanques blindados nas fotografias contrasta com a descrição do caráter pacífico das ocupações. Como na chamada de capa do jornal O Globo de 29 de abril: "A polícia conseguiu retomar o Morro do Borel, que durante décadas foi um perigoso reduto do crime, libertando cerca de 20 mil moradores" ${ }^{27}$.

Libertação e retomada são termos a partir dos quais se estruturam os sentidos das narrativas sobre a ação das UPPs. Não pretendo aqui problematizar os efeitos das UPPs sobre o cotidiano dos moradores, tema que merecia outra análise, mas investigar os efeitos discursivos e políticos de sua implantação. Como afirmei, do ponto de vista jornalístico, elas tiveram o mérito de trazer novos temas ao debate público, como a produção cultural vinda das favelas. Do ponto de vista político, produziram um fenômeno eleitoral há muito não visto: a reeleição, ainda em primeiro turno, do governador Sérgio Cabral, cuja campanha teve as UPPs como uma das principais bandeiras.

Para ilustrar nosso argumento, selecionamos a edição do dia 3 de outubro, dia do pleito, na qual o candidato do PMDB aparece caminhando de muletas pelo Morro Santa Marta, ao lado de políticos, moradores e de uma policial. O texto descreve assim a visita: "Ontem, para o último dia de campanha, Cabral visitou uma UPP, uma das principais bandeiras de sua candidatura. Ele foi ao Morro Dona Marta, primeira favela pacificada no Rio, em dezembro de 2008. E prometeu, além da construção de 64 moradias na comunidade, aumentar o efetivo da Polícia Militar dos atuais cerca de 40 mil policiais para 65 mil até 2014 ”28.

Na primeira entrevista após a reeleição, em 10 de outubro, o governador reforça sua promessa, revelando a centralidade do controle sobre a favela como questão pública. A pergunta do repórter reforça o tema: "Uma de suas promessas é levar UPPs a todas as comunidades do estado dominadas pelo tráfico e pela milícia. Quantas UPPs serão?”29.

Pouco mais de um mês depois, a Guerra com todas as cores estaria de volta aos jornais. Após uma série de ataques a coletivos, e com apoio da Marinha, a cúpula de segurança do Rio decide invadir a Vila Cruzeiro, onde estariam os traficantes responsáveis pelos ataques à cidade. As imagens da incursão do Bope e dos traficantes em fuga pela mata para o Complexo do Alemão rodaram o mundo e garantiram, em 2011, um prêmio Emmy, na categoria notícia, para o Jornal Nacional, da Rede Globo.

No jornal O Globo, interessa-nos, em particular, a edição do dia 26 de novembro, que dedica um caderno especial à cobertura, trazendo como manchete principal "O Dia D da guerra ao tráfico" 29 . A narrativa associa os eventos ocorridos no Rio de Janeiro ao desembarque das tropas aliadas na Normandia, episódio conhecido como Dia D, que deu início à decorada nazista. O comandante do Estado-Maior da PM, coronel Álvaro Garcia assim justifica a invasão da favela: "Esta região sempre trouxe transtorno para a cidade, e agora chegamos aqui para resolver" ${ }^{30}$.

A discussão não se limita mais à questão do território sitiado, mas avança no sentido de interrogar se os traficantes seriam, de fato, uma organização terrorista. São os criminologistas, os especialistas em operações militares e os estudiosos de guerra que vão responder, oferecendo ao leitor um aparato teórico e analítico a partir do qual se posicionar.

Em 16 páginas, produzidas por 45 profissionais, entre repórteres, redatores e editores-assistentes, além de três diagramadores, se empregam técnicas de cobertura de guerra para analisar o evento. Primeiro, a recorrência a imagens de destruição, como o ônibus queimando, embora o episódio se passe a quilômetros de distância da Vila Cruzeiro. Outra característica específica aproxima a cobertura das reportagens sobre guerra ao terrorismo: a técnica de apuração e redação que desloca o leitor para o centro dos acontecimentos. Depoimentos dos repórteres em primeira pessoa, infográficos e até a descrição de um passeio dentro de um tanque de guerra fazem parte do repertório discursivo.

Estes elementos estruturam e ancoram a cobertura, produzindo um consenso a respeito dos significados dos fatos reportados. “A guerra do Rio”, como de costume, é o antetítulo que permeia toda a cobertura, no alto da página. Mas a imagem-símbolo, desta vez, não são os fuzis dos traficantes, mas é o M-113, veículo 
blindado da Marinha que roda sobre uma esteira, o que o torna invulnerável diante dos obstáculos colocados nos acessos à favela.

A cobertura continua nos dias seguintes, tendo seu ápice no dia 29 de novembro, que representa o fim das operações e a "vitória" sobre os inimigos do Complexo do Alemão, onde se dá a ação. Esta, em particular, utiliza fartamente símbolos ligados à guerra e à vitória, como a foto de dois policiais sob o teleférico do Alemão, com uma bandeira do Brasil hasteada, outra imagem de soldados surgindo heroicamente entre cortinas de fumaça e até uma pomba branca, simbolizando a paz. A Guerra do Rio é explicitamente utilizada para enquadrar os sentidos e justificar a operação. Como se pode observar, a chegada das UPPs aos territórios favelados possibilitou o surgimento de novas questões públicas, mas não suplantou o enquadramento principal a partir do qual a favela é assimilada pelo senso-comum.

\section{Considerações finais}

Como argumentei neste trabalho, a produção de uma representação da favela indissociável da violência expressa muito mais do que uma forma, entre outras, de fazer jornalismo. Há, sem dúvida, um projeto político que busca naturalizar a militarização da vida nas favelas, em prol de uma representação de cidade harmônica e sem riscos. Ao logo da nossa pesquisa, identificamos não apenas o agendamento, mas efetivamente o protagonismo da mídia na produção de narrativas que vão influenciar a sociedade, tanto no nível político, quanto no da sociabilidade.

Se há outras soluções em discussão para combater a criminalidade urbana, em particular o tráfico de drogas, elas não estão no noticiário sobre a favela. Os termos favela e violência se identificam num único nível, o da guerra, uma metáfora que ganhou forma nos anos 1990, mas foi reapropriada e ressignificada muitas vezes no noticiário, até que a metáfora se tornou metonímia. Ela agora significa a favela.

Consideramos que os efeitos dos discursos que produzem os sentidos da guerra estão, em boa medida, expressos no próprio noticiário, nos permitindo compreender como o agendamento da mídia atua na sociedade. $\mathrm{O}$ exemplo mais recente aconteceu enquanto terminava este artigo. Após dias de negociações entre o Ministério da Defesa e o governo do Estado do Rio de Janeiro, as tropas federais se juntaram às estaduais para invadirem a Rocinha. $\mathrm{O}$ anúncio se deu poucas horas depois de a TV Globo iniciar a cobertura ao vivo dos confrontos entre traficantes pela posse do território. O título da cobertura no canto da tela nos informa sobre os significados da notícia: Guerra da Rocinha.

\section{Referências}

1. É guerra. Extra. 2017 set. [citado em 2017 Set 22]. Disponível em: https://goo.gl/aJgjb4

2. McCombs M. A teoria da agenda. Mídia e opinião pública. 19 ed. Petrópolis, RJ: Vozes; 2009.

3. Walter L. Public Opinion. New York: The Free Press; 1965.

4. Entman R. Framing: Toward clarification of a fractured paradigma. J. commun. 1993; 43(4):51-8

5. Benevides MV. Violência, povo e polícia. Violência no noticiário da imprensa. São Paulo: Brasilienses; 1983.

6. Roberto Marinho: ouvimos o povo e buscamos soluções. O Globo. 1984 Ago. 29:12.

7. Rio já tem 3 milhões de assaltados. Jornal do Brasil. 1986 Jul. 14:Capa.

8. Silva LAM. Sociabilidade violenta: por uma interpretação da criminalidade contemporânea no Brasil urbano. Soc. Estado. 2004; 19(1):53-84

9. Mollenkopf JH, Castells M, editores. Dual City: Restructuring New York. New York: Russell Sage Foundation; 1992. (City in the Twenty-First Century).

10. Vaz P, Sá-Carvalho M, Pombo M. Risco e sofrimento evitável: a imagem da polícia no noticiário de crime. E-Compos. 2005;1- 22 
11. A batalha de Acari. O Globo. 1993 Set. 29:13

12. Itamar se diz horrorizado. Jornal do Brasil. 1993 Jul. 24:2

13. Traficantes privatizaram a favela. O Globo. 1993 Set. 26:8.

14. Exército e PF poderão ocupar morros. O Globo. 1993 Set. 26:15.

15. "A polícia não está nem aí". O Globo. 1994 Set. 02:11.

16. Exército realiza maior operação na Zona Sul. Jornal do Brasil. 1994 Dez. 16:21.

17. Exército aceita desafio e ocupa morro. O Globo. 1994 Dez. 20:17.

18. Militares ocupam 11 favelas do Alemão. O Globo. 1995 Jan. 13.

19. Ministro do STJ é espancado por ladrões. Jornal do Brasil. 2003 Maio 25:Capa.

20. A conta da insegurança. O Globo. 2003 Abr. 6:21.

21. Favelas em confronto, perigo no asfalto. O Globo. 2003 Dez. 27:9.

22. Pavor de madrugada, medo no resto do dia. O Globo. 2004 Jan 23:14.

23. Gangan é sepultado com gritos de guerra. O Globo. 2004 Out. 15:20.

24. Vidas roubadas pelo medo. Jornal do Brasil. 2004 Abr. 15:1.

25. A cidade Partida. Jornal do Brasil.2004 Abr. 15:2:(JB Barra).

26. Hildegard Angel. Jornal do Brasil. 2004 Abr. 15:17: (Cidade A).

27. PM ocupa sete favelas da Tijuca sem nenhum tiro. O Globo. 2010 Abr. 29: Capa.

28. Cabral em céu de brigadeiro, e turbulências para o Senado. O Globo. 2010 Out. 3:39.

29. A população percebeu que não foi só UPP. O Globo. 2010 Out. 10:22.

30. O Dia D da guerra ao tráfico. O Globo.2010 Nov. 26:Capa.

31. A reconquista da Vila Cruzeiro. O Globo. 2010 Nov. 26:2:(Especial). 